\title{
As assinaturas gráficas da Typographia do Diario Official do Estado de São Paulo: 1891-1911
}

The graphic signatures of the Typographia do Diario Official do Estado de São Paulo: 1891-1911

\author{
PEREIRA, Fabio Mariano Cruz; Doutorando; Universidade de São Paulo
}

fabiomcpereira@gmail.com

FARIAS, Priscila L.; Doutora; Universidade de São Paulo

prifarias@usp.br

\begin{abstract}
Resumo
Este artigo apresenta os resultados de uma pesquisa cujo objetivo principal foi identificar as características visuais das "assinaturas gráficas" da Typographia do Diario Official do Estado de São Paulo presentes nas imprentas de livros publicados entre os anos 1891 e 1911. Entende-se por imprenta o conjunto de informações presentes nas folhas de rosto, indicando cidade, ano e "assinatura gráfica" (nome da gráfica ou editora). O método adotado baseia-se em coleta e seleção de folhas de rosto do período e análises gráficas tanto das folhas de rosto quanto das imprentas nelas contidas. Foram identificadas composições que caracterizaram as imprentas e as folhas de rosto da época, especialmente quanto à hierarquia de informação. Espera-se, com este estudo, contribuir para uma compreensão mais apurada da história do design brasileiro no começo do século XX.
\end{abstract}

Palavras Chave: Assinatura gráfica; imprenta; folha de rosto; Diário Oficial

\begin{abstract}
This article presents the results of a research whose main objective was to identify the visual characteristics of the Typographia do Diario Official do Estado de São Paulo's "graphic signatures" present in the imprints of books published between 1891 and 1911. By imprint we understand the information present in title pages indicating place, year and "graphic signature" (printing office's name). The method proposed involved the collection and selection of title pages produced in the period, and the graphic analysis of title pages and imprints. Compositions that characterize imprints and title pages of that period were identified, especially in what regards hierarchy of information. With this study, we hope to contribute to a more accurate understanding of early twentieth century Brazilian design history.
\end{abstract}

Keywords: Graphic signature; imprint; title page; Diário Oficial 


\title{
1 Introdução
}

O estudo apresentado neste artigo teve por objetivo identificar as principais características visuais das assinaturas gráficas da Typographia do Diario Official do Estado de São Paulo presentes nas imprentas das folhas de rosto de livros publicados entre 1891 e 1911 . Tal período corresponde às duas primeiras décadas de funcionamento desta oficina tipográfica, quando foi chefiada por Elviro da Cunha Leal. Os chefes da Typographia do Diario Official eram responsáveis, entre outras atribuições, por "designar o tipo e o formato que deve ter qualquer obra ou expediente, interferindo na escolha das letras de títulos, emblemas, vinhetas, etc." (Diário Oficial 1891: 3). Além disso, eram responsáveis também por aprovar as fôrmas tipográficas para impressão e ainda "entender-se com os impressores sobre a qualidade e o formato do papel a ser usado" (Diário Oficial 1891: 4) - decisões consideradas pertinentes ao design gráfico. Presume-se, assim, que Elviro da Cunha Leal tivesse um olhar sensível em relação à composição do nome da oficina tipográfica por ele chefiada.

A definição de design gráfico é aqui entendida como aquela proposta por Newark (2009: 34), indicando a produção em série de moedas na Grécia antiga como marco pioneiro, e fazendo referência à disseminação dos tipos móveis como atividade que aprimorou um raciocínio específico para seriação de páginas impressas. Nesta acepção, pode-se dizer que os tipógrafos do começo do século XX, decidindo sobre aspectos de impressão, já estavam exercendo funções próximas ao que hoje se entende por design gráfico.

O termo assinatura gráfica aqui utilizado se refere à composição tipográfica de nomes criados para identificar e/ou diferenciar produtos, empresas ou serviços, concebidos graficamente, mas não necessariamente reproduzidos de modo sistêmico. Tal definição foi detalhada por Piaia (2017) ao estudar as diferentes manifestações da comunicação institucional da Pinacoteca do Estado de São Paulo. A autora define assinatura gráfica como

\begin{abstract}
um nome, seja de uma pessoa, empresa - produto/serviço -, ou instituição, envolvendo ou não elementos esquemáticos, pictóricos ou abstratos no modo como é reproduzida, através de processos de impressão gráfica, técnica que origina essa terminologia. Abrange o universo das artes gráficas, incluindo tanto os campos profissionais gráficos anteriores ao período de institucionalização do que se conhece hoje como design, quanto o campo profissional configurado a partir deste último. Compreende também o uso de tipografias prontas na composição visual de nomes institucionais ou comerciais, confeccionados ainda sem a intenção de projeto, como este é entendido hoje pelo campo do design gráfico. (Piaia 2017: 50)
\end{abstract}

O termo se coloca em paralelo a assinatura visual, proposto por Strunck (1989) para designar a combinação do logotipo (nome composto e reproduzido de forma particularizada) com o símbolo (forma gráfica não-verbal concebida e estabelecida para representar um serviço ou produto) (Strunck 1989: 16). Considera-se, entretanto, que este conceito seja mais adequado ao entendimento atual do design e menos aos artefatos produzidos antes da institucionalização do ensino formal de design no Brasil.

Uma assinatura gráfica, tal como foi definida por Piaia (2017), pode ser encontrada em diferentes suportes físicos, incluindo folhas de rosto de livros impressos, neste caso estando tradicionalmente relacionada ao agrupamento de informações denominado imprenta. Segundo Rossi Filho (2001), imprenta é o "conjunto de informações que identificam a editora, o endereço, a data de edição etc., impressas no pé da página de rosto de uma publicação" (Rossi Filho 2001: 
325). Em Diccionario de Termos Graphicos, primeira referência técnica ao campo tipográfico produzida no Brasil, Arezio (1936) define imprenta como "endereço ou reclame da oficina que se coloca no pé de página, da capa ou frontispício, ou na última página do livro. O mesmo que colofão" (Arezio 1936: 422).

Há uma diferença importante, porém, entre as duas definições. A mais recente compreende imprenta como um recurso de identificação da editora; a mais antiga compreende imprenta como um possível reclame da oficina tipográfica, sugerindo que as composições dos nomes das tipografias nas folhas de rosto podiam ir além de uma função simplesmente informativa. Neste sentido, compreender a composição de antigas imprentas pode revelar aspectos históricos ligados às diferentes formas de representação das tipografias paulistanas. Tal interesse faz parte de uma pesquisa mais ampla, em andamento, desenvolvida pelo primeiro autor deste artigo, na qual se busca identificar e descrever as principais características da comunicação institucional das oficinas tipográficas que atuaram na capital paulista no começo do século XX.

O campo gráfico do período foi marcado pelo crescimento urbano de São Paulo, com especial influência de comunidades imigrantes e da expansão das fábricas de papel (Gordinho 1991: 40 e 43). Houve também a consolidação das associações de tipógrafos (Vitorino 2000: 121 e 205) e a popularização das revistas comerciais (Martins 2008: 41-44), contexto que se mostrava estimulante para o desenvolvimento das oficinas tipográficas, que concorriam num mercado relativamente maduro. Este cenário era, porém, muito diferente do início do século XIX, quando sequer havia uma oficina tipográfica na cidade, já que a história da imprensa paulista é, pode-se dizer, recente ${ }^{1}$.

São Paulo só passou a imprimir com tipos móveis em 1827, 19 anos depois da chegada de Dom João VI e da permissão para funcionamento de oficinas tipográficas particulares. O periódico O Farol Paulistano inaugurou a imprensa em São Paulo por iniciativa de José da Costa Carvalho (Ipanema 2008: 10). Em 1834, a oficina tipográfica passou a publicar o bissemanário $O$ Paulista Official, que foi comprado pelo governo da província, em 1835, para publicação dos atos oficiais e substituído posteriormente pelo O Paulista Centralizador. A oficina do governo funcionou precariamente, chegando a ser arrendada por três anos, levando o poder público a contratar outras oficinas tipográficas para atender à demanda de impressos (Tálamo 1983: 22).

Com a instauração da república, renovou-se o interesse por uma oficina tipográfica oficial. O decreto n.162, de 28 de abril de 1891, criou a Typographia do Estado - como foi inicialmente chamada -, que passou a funcionar nos fundos da antiga Igreja dos Remédios, depois de adquirir o material tipográfico do extinto jornal abolicionista A Redenção (Maranhão 1994: 47).

Segundo Maranhão (1994), a tipografia d'A Redenção estava parada havia

dois anos, estava desfalcada e desmantelada. Não tinha minerva nem guilhotina. Também não tinha tipos para impressão de obras, e os destinados ao jornal eram poucos e estavam em mau estado. Não havia equipamentos para encadernação e durante algum tempo esse serviço foi realizado em outra oficina (Maranhão 1994: 47).

\footnotetext{
${ }^{1}$ Para um maior aprofundamento sobre a história da tipografia em São Paulo, especialmente no que diz respeito à prática de fundir e comercializar tipos, recomenda-se a leitura de Aragão (2016).
} 
João José Araújo, primeiro diretor da Typographia do Diario Official, tratou logo de encomendar da Europa equipamentos para impressão e encadernação, mas sua curta gestão inviabilizou a instalação dos novos equipamentos que permaneceram retidos no porto de Santos até a intervenção, quatro anos depois, do segundo diretor, Horácio de Carvalho, na ocasião em que a oficina tipográfica mudou para a Rua Onze de Agosto, onde funcionou pelos 37 anos seguintes em um espaço considerado insuficiente (Maranhão 1994: 23).

Quase nada se sabe sobre Elviro da Cunha Leal, chefe da Typographia do Diario Official. Os poucos registros encontrados em jornais da época, como $O$ Estado de S. Paulo, o próprio Diario Official e o extinto Correio Paulistano, relatam que era viúvo em 1899, tendo perdido uma filha em 1879 e uma neta em 1909. Sabe-se também que em 1891 foi nomeado chefe da Typographia do Diario Official e que esteve na Europa em 1910. Não há dados sobre sua formação, embora seus dois filhos, Ruben da Cunha Leal e Elviro da Cunha Leal Junior também tenham seguido carreira na imprensa; o primeiro assumindo a chefia da Typographia do Diario Official assim que o pai aposentou em 1911, e o segundo como tipógrafo - também no Diario Official -, em 1924. Elviro da Cunha Leal faleceu em 1920, em Portugal.

A pesquisa relatada neste trabalho baseou-se em análises qualitativas, com abordagem da micro-história ao iluminar "aquilo que escapa à macro-história tradicional, empreendendo uma 'redução da escala de observação' que não poupa os detalhes e que investe no exame intensivo de uma documentação" (Barros 2007: 170). Foram selecionadas folhas de rosto de publicações não-periódicas impressas pela Typographia do Diario Official entre os anos 1891 e 1911 e disponíveis fisicamente nas bibliotecas cadastradas no sistema SIBiUSP (Sistema Integrado de Bibliotecas da Universidade de São Paulo). Pressupôs-se que artefatos gráficos produzidos pelo Estado teriam sido preservados pelo próprio Estado, constituindo uma amostra coerente para a pesquisa. A partir das folhas de rosto encontradas foi selecionado um grupo de 13 assinaturas gráficas, posteriormente submetidas à análise.

\section{As folhas de rosto do Diario Official}

As folhas de rosto foram localizadas pelo portal <dedalus.usp.br>, a partir do argumento "diário official" no campo de busca "editora". Do volume retornado, foram selecionados apenas itens datados entre 1891 e 1911, resultando uma lista de 121 publicações espalhadas em diferentes bibliotecas ${ }^{2}$. Foram realizadas, então, visitas presenciais em cada uma destas bibliotecas, ocasião em que as folhas de rosto foram fotografadas em alta resolução e medidas com escalímetro na unidade centímetro. Foram dispensadas as visitas aos acervos cujo volume não ultrapassava dois itens, pois considerou-se que, nestes casos, os dados a serem coletados não compensariam o deslocamento e transporte de equipamento fotográfico. Da mesma forma, alguns itens, não estando disponíveis no momento da consulta, não fizeram parte da pesquisa.

As fotografias dos itens consultados foram nomeadas de modo padronizado, conforme o exemplo abaixo:

\footnotetext{
${ }^{2}$ Escola Politécnica (EP); Faculdade de Direito (FD); Museu Republicano (MR); Museu Paulista (MP); Faculdade de Educação (FE); Instituto de Estudos Brasileiros (IEB); Faculdade de Economia, Administração e Contabilidade (FEA); Faculdade de Filosofia, Letras e Ciências Humanas (FFLCH); Faculdade de Medicina (FM); Biblioteca Brasiliana Mindlin (BBM); Faculdade de Saúde Pública (FSP); Museu de Arqueologia e Etnologia (MAE); Escola Superior de Agricultura Luiz de Queiroz (ESALQ); e Museu de Zoologia (MZ).
} 
001_DO_assi_EP_1891, onde: 001 corresponde ao número atribuído ao volume consultado; DO corresponde à sigla da oficina tipográfica que imprimiu o impresso (neste caso, Diario Official); assi corresponde à sigla do objeto de estudo (neste caso, assinatura gráfica); EP corresponde à sigla do acervo consultado (neste caso, Escola Politécnica); e 1891 corresponde ao ano em que o item foi impresso.

De acordo com Arezio (1936), a folha de rosto é a "página do livro onde geralmente há o título da obra, o nome do autor ou tradutor, e a designação da oficina ou do editor" (Arezio 1936: 490). Entende-se, portanto, que, sendo as folhas de rosto os suportes das assinaturas gráficas das oficinas, é razoável que as análises destas assinaturas gráficas procedam a partir das análises das folhas de rosto.

Tschichold (2007) dedica um capítulo inteiro à importância da composição de uma folha de rosto, entendendo-a como elemento fundamental à estrutura do livro. Para o autor, o espaço branco entre o título e a imprenta deve ser cuidadosamente equilibrado com os outros elementos da página. Se houver, por exemplo, símbolo do editor,

convém que se harmonize suavemente com a tipografia e que as linhas mais grossas não sejam mais grossas do que as linhas mais grossas do maior tipo empregado no título, nem que suas linhas mais finas sejam mais finas do que as linhas mais finas do menor tipo usado (Tschichold 2007: 96).

De Vinne (1904) também descreve uma série de recomendações para a composição de uma "boa" folha de rosto, que vão desde a distribuição dos espaços brancos na página à escolha dos tipos e das palavras a serem enfatizadas (De Vinne 1904: 111-127).

A descrição apresentada por França \& Sant'Anna (2006), quando da análise das folhas de rosto de livros de leis provinciais do Espírito Santo, apresenta categorias informacionais baseadas no conteúdo verbal e divididas em linhas compostas em diferentes tipos: identificação da obra, província, descrição, tomo, brasão, assinatura e data.

O modelo de análise gráfica proposto por Villas-Boas (2009), por sua vez, se aplica a uma diversidade de layouts, sendo baseado em: elementos técnico-formais, referentes aos princípios percebidos intuitivamente (síntese, harmonia, balanceamento, hierarquia, etc.); e elementos estético-formais, referentes a componentes efetivamente impressos (textos, grafismos, ilustrações, etc.). Para o estudo aqui apresentado, buscou-se unir o modelo de França \& Sant'Anna (2006) ao de Villas-Boas (2009), conjugando a descrição de categorias informacionais com elementos estético-formais.

Cada uma das folhas de rosto encontradas apresenta ao menos três agrupamentos distintos de informações: título (situado na parte superior da página), elemento pictórico (situado na região imediatamente inferior ao centro geométrico ${ }^{3}$ da página) e imprenta (situada no pé da página).

No agrupamento título foram encontradas diferentes famílias tipográficas, destacando as categorias informacionais autoria, destinatário, descrição da obra, lugar, data etc., além de

\footnotetext{
${ }^{3} \mathrm{O}$ centro geométrico indica o ponto central do quadrilátero que compõe a página (encontro das linhas que dividem em duas partes iguais a largura e a altura). Sua referência mais próxima é o centro óptico, um pouco acima do geométrico, indicando a região de maior interesse para a visão humana em relação à página. Ambos os referenciais compositivos são indispensáveis ao "centramento", dispositivo que contribui para organização de um layout (VillasBoas 2009: 13).
} 
informações menores, tais como preposições, conjunções ou artigos. No agrupamento elemento pictórico foram encontrados brasões, ornamentos e fios. No agrupamento imprenta, quase sempre organizado em três linhas, foram encontradas as categorias informacionais cidade, nome da oficina (aqui entendida como assinatura gráfica) e ano (figura 1).

Figura 1. Grupos de informações presentes nas folhas de rosto encontradas.

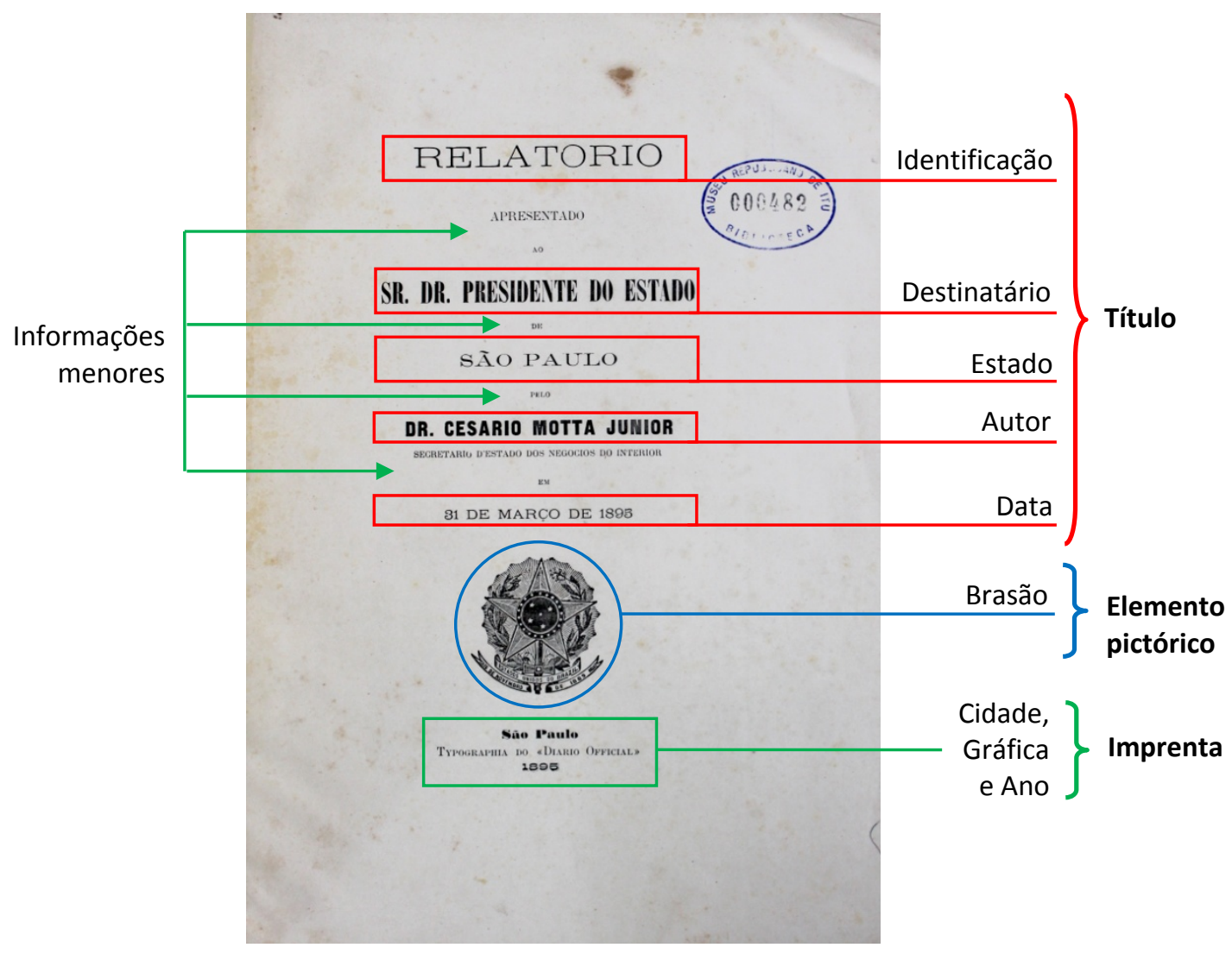

Observou-se que a maioria das obras impressas pelo Diário Oficial tem caráter governamental e administrativo, constituindo um grupo de diferentes espécies documentais ${ }^{4}$. A análise hierárquica das informações foi orientada em razão das linhas textuais em destaque e não em razão do conteúdo verbal, podendo, assim, um mesmo título apresentar hierarquias diferentes em cada uma de suas linhas. Segundo O'Grady (2008), "no contexto do design gráfico, 'hierarquia' refere-se ao ordenamento do conjunto de informações pictóricas e tipográficas de modo que um leitor possa rapidamente entender sua importância relativa" (O'Grady 2008: 105). A composição de uma página pode, com uso de recursos como diferenças tipográficas, grids, alinhamentos, contrastes ou cores, orientar o leitor.

$\mathrm{Na}$ análise hierárquica procedida neste estudo foi adotada a seguinte ordem de importância: tamanho (altura das letras); posição (distância do centro óptico da página); peso (espessura dos traços das letras, ou variação de espessura); e estilo tipográfico (uso de letras incomuns, ornamentadas, cursivas, itálicas ou góticas). Com base nesta ordem de importância, as

\footnotetext{
${ }^{4}$ A diplomática entende a espécie documental como o documento que "obedece a fórmulas convencionadas, em geral estabelecidas pelo Direito administrativo ou notarial" (Bellotto 2002: 27).
} 
informações contidas em cada folha de rosto receberam até 5 posições hierárquicas diferentes (muito destacada, destacada, pouco destacada, discreta e muito discreta).

Foi elaborado um modelo descritivo para análise de folhas de rosto (figura 2) baseado nos seguintes atributos:

- Formato do item analisado (largura $\mathrm{x}$ altura, em centímetros);

- Identificação do item analisado (se relatório, ato, projeto, lei, decreto, regulamento, regimento, coleção etc.);

- Hierarquia informacional (compreendendo as posições: 1 - muito destacada, 2 destacada, 3 - pouco destacada, 4 - discreta, 5 - muito discreta);

- Acervo (sigla da biblioteca em que se encontra a publicação);

- Localização (número de chamada do item dentro do sistema SIBiUSP);

- Ano.

Figura 2: Ficha para descrição de folhas de rosto (adaptada da planilha em Excel).

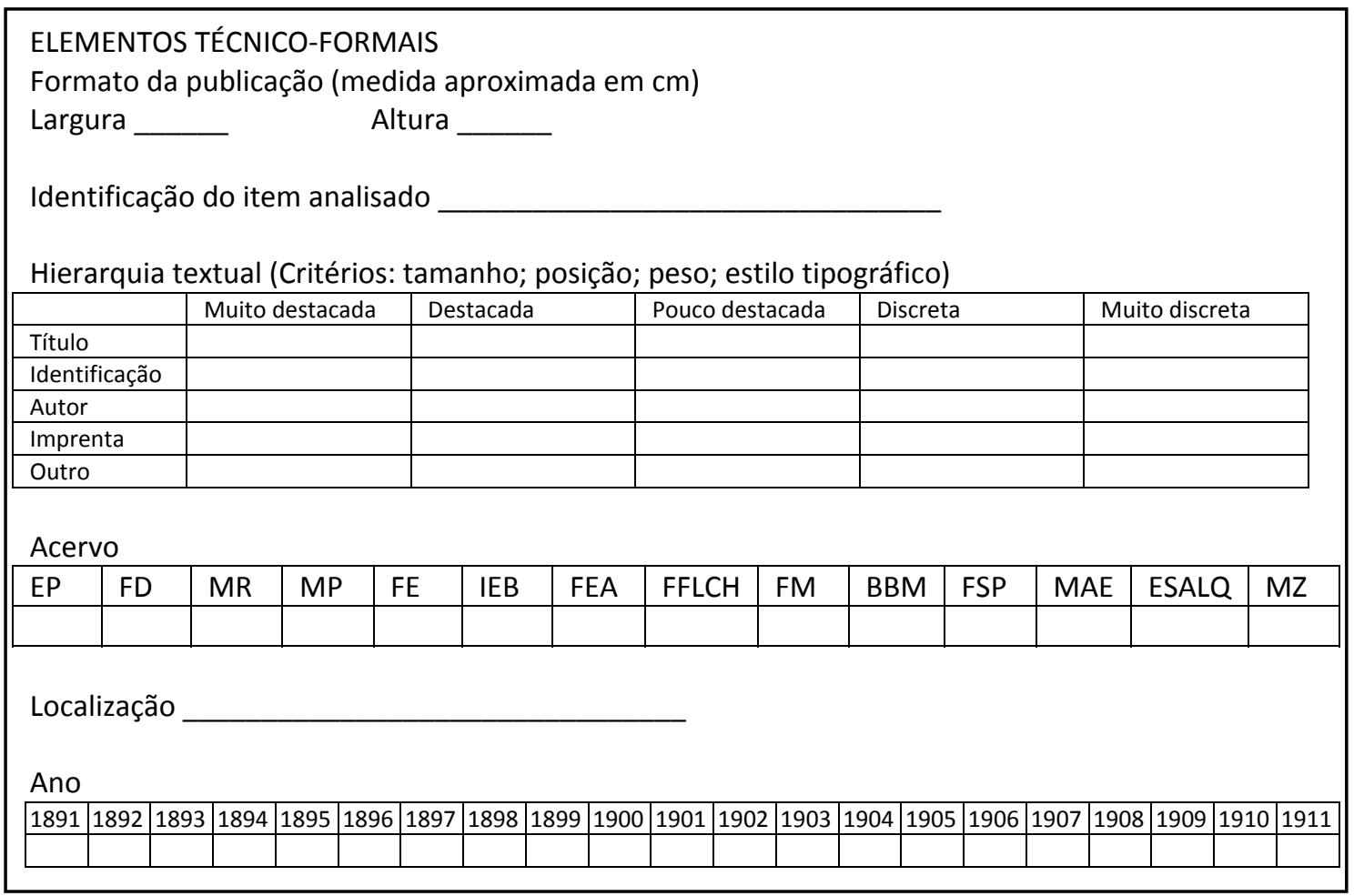

\section{As assinaturas da Typographia do Diario Official}

Todas as imprentas encontradas foram ampliadas, impressas e coladas sobre papel craft, concebendo-se um painel de aproximadamente $2,23 \mathrm{~m}$ de largura por $0,65 \mathrm{~m}$ de altura. Este procedimento foi adotado para permitir uma visão panorâmica das assinaturas gráficas, o que facilitou uma categorização inicial baseada nos critérios: grafia (diferentes formas de grafar o nome da oficina tipográfica) e variações tipográficas (diferentes recursos tipográficos usados para compor o nome da oficina tipográfica) (tabela 1). 
Tabela 1. Categorização do nome da oficina tipográfica nas imprentas encontradas.

\begin{tabular}{|l|l|l|l|l|}
\hline \multirow{2}{*}{ Critério: Grafia } & \multicolumn{4}{l|}{ Critério: variaçao tipográfica } \\
\cline { 2 - 5 } & caixa-alta & versalete & versal/versalete & itálico \\
\hline Grafia 1 - DIARIO OFFICIAL & $1 \mathrm{ca}$ & $1 \mathrm{v}$ & $1 \mathrm{v} / \mathrm{v}$ & 1 it \\
\hline Grafia 2 - TYPOGRAPHIA DO DIARIO OFFICIAL & $2 \mathrm{ca}$ & $2 \mathrm{v}$ & $2 \mathrm{v} / \mathrm{v}$ & $2 \mathrm{it}$ \\
\hline Grafia 3 - TYP. DO DIARIO OFFICIAL & $3 \mathrm{ca}$ & $3 \mathrm{v}$ & $3 \mathrm{v} / \mathrm{v}$ & $3 \mathrm{it}$ \\
\hline Grafia 4 - TYPOGRAPHIA DO «DIARIO OFFICIAL» & $4 \mathrm{ca}$ & $4 \mathrm{v}$ & $4 \mathrm{v} / \mathrm{v}$ & 4 it \\
\hline Grafia 5 - TY. DO «DIARIO OFFICIAL» & $5 \mathrm{ca}$ & $5 \mathrm{v}$ & $5 \mathrm{v} / \mathrm{v}$ & $5 \mathrm{it}$ \\
\hline
\end{tabular}

A partir dos resultados obtidos na análise das folhas de rosto, foi selecionado um grupo reduzido de assinaturas gráficas. Para isto, foram excluídas as repetições, mantendo-se apenas as primeiras ocorrências das sequências que continham assinaturas semelhantes. $O$ início das sequências de assinaturas semelhantes tem especial interesse neste trabalho, pois equivalem a momentos de mudanças no hábito de composição das imprentas. Foi criado, então, um modelo descritivo específico para análise de imprentas, baseado no conjunto coletado. O modelo tem enfoque na assinatura gráfica, atentando-se para características tipográficas (figura3).

Figura 3: Assinatura gráfica presente em imprenta de folha de rosto.

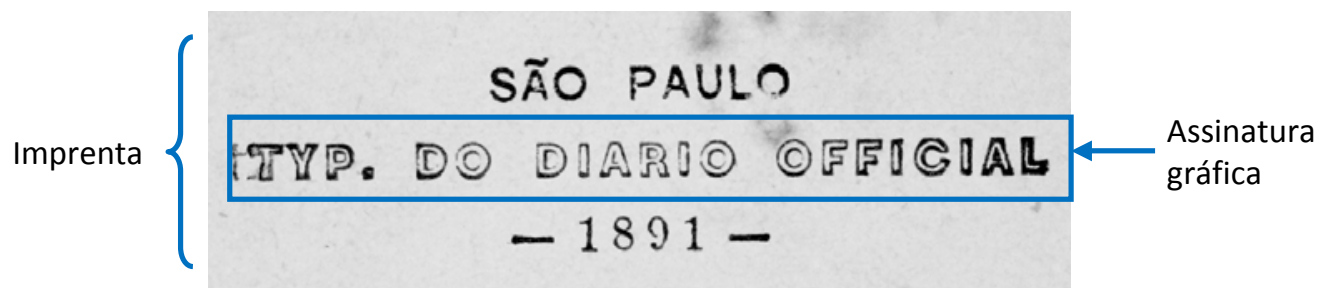

Em tal análise, foi adotada a classificação BS 2961, proposta pela British Standards Institution, em 1967, a partir do modelo de Maximilien Vox 5 . O modelo BS 2961 adota as seguintes classes tipográficas: humanista, garaldina, transicional, didônica, egipciana, linear grotesca, linear neo-grotesca, linear geométrica, linear humanista, glífica, escritural e gráfica. (Tracy 1971: 64-65; Silva \& Farias 2005: 74). Este modelo é interessante, pois permite agrupar fontes a partir de características mínimas observadas em um grupo reduzido de caracteres. Em geral, as assinaturas gráficas encontradas são compostas em uma única e curta linha de tipos, com um determinado agrupamento de caracteres tipográficos em caixa-alta ou versalete ${ }^{6}$.

O modelo descritivo elaborado para análise das imprentas selecionadas (figura 4) foi baseado nos seguintes atributos formais:

- Elementos esquemáticos: referindo-se a presença de formas abstratas não-verbais, a exemplo de fios, vinhetas e ornamentos tipográficos (Twymann 1979: 143);

- Combinação tipográfica: campo destinado à classificação tipográfica identificada em cada linha da imprenta;

\footnotetext{
${ }^{5}$ Tipógrafo francês que apresentou, em 1954, uma classificação tipográfica cunhando termos baseados em marcos e personagens históricos. Seu esquema viria a influenciar as classificações tipográficas posteriores (Tracy 1971: 61).

${ }^{6}$ Versaletes são letras que possuem o mesmo desenho das maiúsculas, mas de altura similar à altura-x das minúsculas. Diferem das maiúsculas tanto no peso quanto nas proporções (Bringhurst 2005: 58).
} 
- Repetição tipográfica: Indica quando a fonte usada no nome da oficina tipográfica foi também usada em outras linhas da folha de rosto;

- Grafia da assinatura: descreve a forma usada para grafar o nome da tipografia;

- Estilo tipográfico da assinatura gráfica: descreve o estilo da fonte usada para compor o nome da tipografia (se romana, itálica, gótica, manuscrita...);

- Variações tipográficas: descreve o tipo de recurso tipográfico usado no nome da tipografia (caixa-alta, caixa-alta e baixa, versalete, versal e versalete, caixa-baixa).

Figura 4. Ficha para descrição de imprentas (adaptada da planilha em Excel).

\section{QUANTO ÀS LINHAS DA IMPRENTA}

Quantidade de linhas

Presença de elementos esquemáticos

\begin{tabular}{|c|c|c|c|c|}
\hline Fios & Ornamentos & Aspas francesas & Aspas francesas e fios & Não há \\
\hline & & & & \\
\hline
\end{tabular}

Combinação tipográfica (segundo classificação BS 2961: 1967)

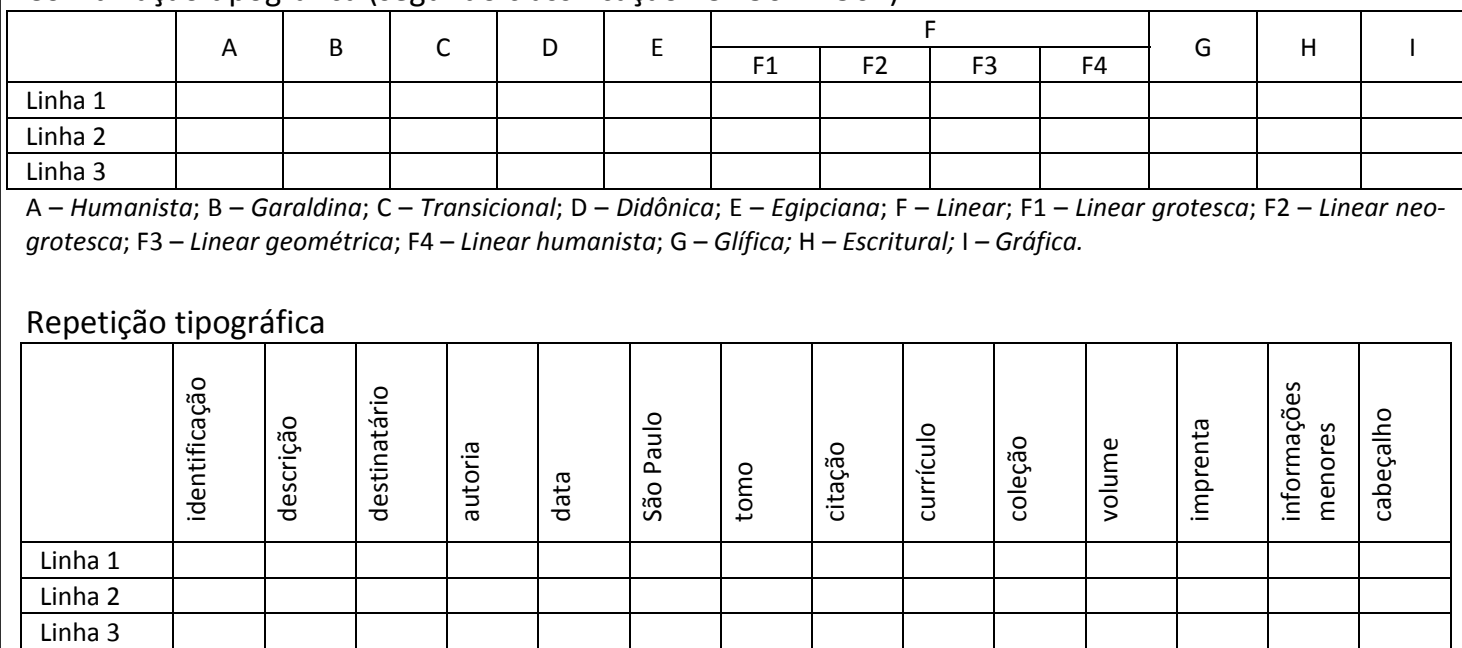

QUANTO À LINHA COM ASSINATURA

Grafia e variação tipográfica

\begin{tabular}{|l|l|l|l|l|l|l|}
\hline & Romano & Itálico & Versal & Versalete & Versal e versalete & $\ldots$ \\
\hline Grafia 1 & & & & & & \\
\hline Grafia 2 & & & & & & \\
\hline Grafia 3 & & & & & & \\
\hline$\ldots$ & & & & & & \\
\hline
\end{tabular}

\section{Resultados encontrados}

Foi analisado um total de 95 folhas de rosto, nas quais as posições hierárquicas 1 (muito destacada) e $\mathbf{2}$ (destacada) estavam presentes nos títulos, nas categorias informacionais identificação e descrição. A posição hierárquica 5 (muito discreta) encontra-se reservada a imprenta e às informações menores do título. 
As relações da hierarquia informacional podem ser visualizadas por meio da tabela $\mathbf{2}$, onde se percebe uma crescente predominância da imprenta na medida em que se diminui a importância dada às informações.

Tabela 2: Hierarquia informacional das folhas de rosto.

\begin{tabular}{|c|c|c|c|c|c|c|c|}
\hline- & 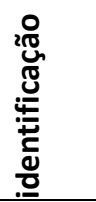 & 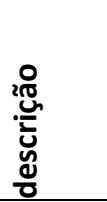 & 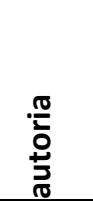 & 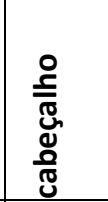 & $\underset{\frac{\pi}{\pi}}{\frac{\pi}{0}}$ & 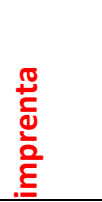 & 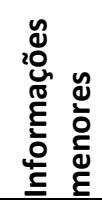 \\
\hline Muito destaque & 40 & 16 & 14 & - & - & - & - \\
\hline Destaque & 31 & 12 & 20 & 7 & 4 & - & - \\
\hline Pouco destaque & 4 & 5 & 36 & 13 & 23 & 7 & 1 \\
\hline Discreto & 1 & 17 & 6 & 8 & 21 & 19 & 6 \\
\hline Muito discreto & - & 1 & 4 & 2 & 6 & 44 & 16 \\
\hline
\end{tabular}

Todos os formatos encontrados nas publicações seguem orientação vertical, com diferenças na largura e na altura. Foram identificados três grupos de formatos semelhantes (figura 5): formato maior, com média aritmética de $22 \times 30,5 \mathrm{~cm}$; formato intermediário, com média aritmética de 14,75 x $22 \mathrm{~cm}$; e formato menor, com média aritmética de 10,5 x 15,5 cm. A maioria das publicações foi concebida no formato intermediário, que se aproxima da proporção baseada na forma geométrica pentagonal, mais confortável à visão e ao manuseio (Bringhurst 2005: 160; Tschichold 2007: 63).

Figura 5: Teste de sobreposição dos formatos de página encontrados.

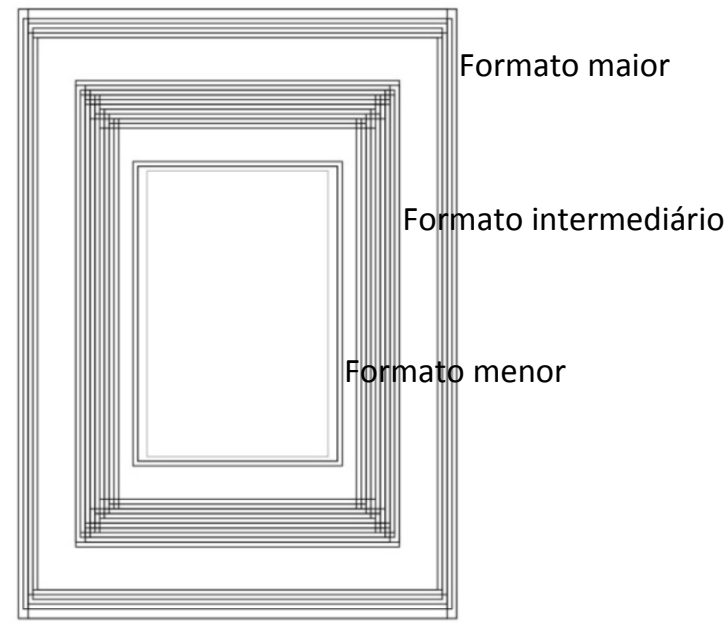

Quanto às assinaturas gráficas, a ocorrência mais comum apresenta palavras sem abreviações, com presença de aspas francesas duplas ${ }^{7}$ (TYPOGRAPHIA DO «DIARIO OFFICIAL») e uso de versaletes. Esta ocorrência foi mais frequente entre os anos 1895 e 1904, contemplando um período de quase dez anos. As fontes itálicas foram usadas apenas nos primeiros quatro anos

\footnotetext{
${ }^{7}$ Aspas francesas pertencem aos alfabetos latino, cirílico e grego, sendo mais comuns nos continentes europeu, asiático e africano. Também chamadas de aspas angulares « » (Bringhurst 2005: 333).
} 
de funcionamento da oficina. De 1895 a 1911, o padrão mais frequente dispensava as aspas francesas, mas mantinha os tipos versaletes (figuras 6 e 7).

Figura 6: Gráfico indicativo da quantidade de categorias de assinaturas gráficas encontradas.

\author{
41
}

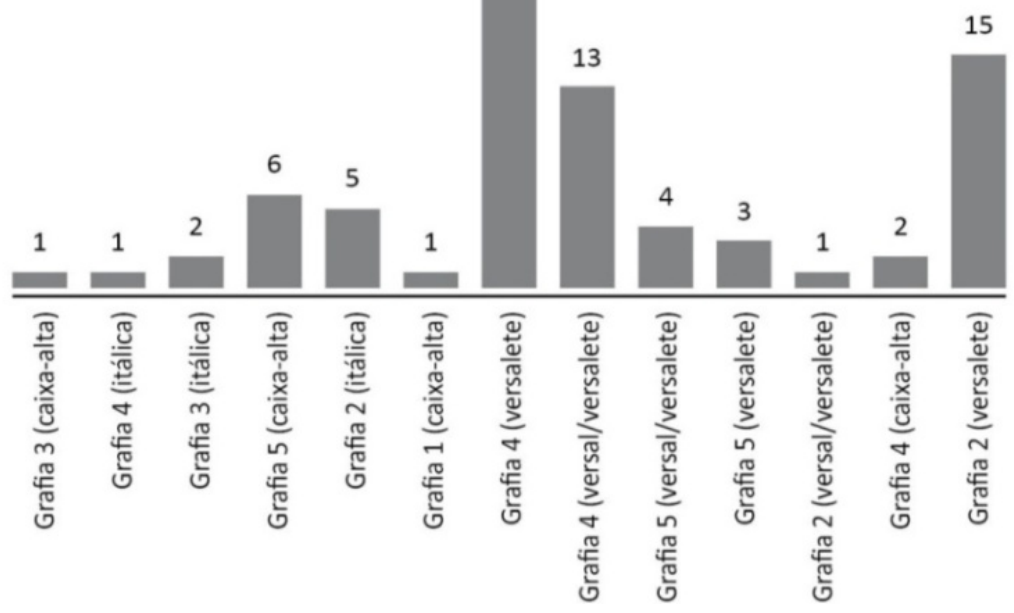

Figura 7: Categorias de assinaturas gráficas em relação ao período em que foram impressas.

\begin{tabular}{|c|c|c|c|c|c|c|c|c|c|c|c|c|c|c|c|c|c|c|c|c|c|}
\hline & ه্- & §్ & $\stackrel{m}{\infty}$ & \$્ઠ & مू & Фั & م્ & 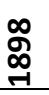 & 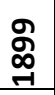 & 욤 & ్ㅗㅇ & ণั & ஓ्. & ষ্ন & 옹 & ঃ̊ & 옥 & $\stackrel{\infty}{\circ}$ & ஓ्. & 옥 & 걱 \\
\hline $3 c a$ & & & & & & & & & & & & & & & & & & & & & \\
\hline 4 it & & & & & & & & & & & & & & & & & & & & & \\
\hline $3 i t$ & & & & & & & & & & & & & & & & & & & & & \\
\hline $5 \mathrm{ca}$ & & & & & & & & & & & & & & & & & & & & & \\
\hline 2 it & & & & & & & & & & & & & & & & & & & & & \\
\hline 1ca & & & & & & & & & & & & & & & & & & & & & \\
\hline $4 v$ & & & & & & & & & & & & & & & & & & & & & \\
\hline $4 \mathrm{v} / \mathrm{v}$ & & & & & & & & & & & & & & & & & & & & & \\
\hline $5 v / v$ & & & & & & & & & & & & & & & & & & & & & \\
\hline $5 \mathrm{v}$ & & & & & & & & & & & & & & & & & & & & & \\
\hline $2 v / v$ & & & & & & & & & & & & & & & & & & & & & \\
\hline $4 \mathrm{ca}$ & & & & & & & & & & & & & & & & & & & & & \\
\hline $2 v$ & & & & & & & & & & & & & & & & & & & & & \\
\hline
\end{tabular}

A análise das assinaturas também revelou predominância de fontes transicionais. Tais fontes representam, historicamente, um período de transição, conservando características de fontes garaldinas e antecipando características de fontes didônicas (Tracy 1971: 64). Foram encontradas diferentes fontes tipográficas usadas nas assinaturas gráficas, além de variações de espaçamento, o que exclui a possibilidade do uso de clichês (figura 8). Esta observação é razoável 
uma vez que a estrutura da oficina era deficitária, dispondo de pouco maquinário, e sem energia elétrica, sugerindo que o acesso a máquinas como linotipo - novidades na época - fosse pouco provável.

Figura 8: Diferenças de fonte e espaçamento nas assinaturas gráficas analisadas.

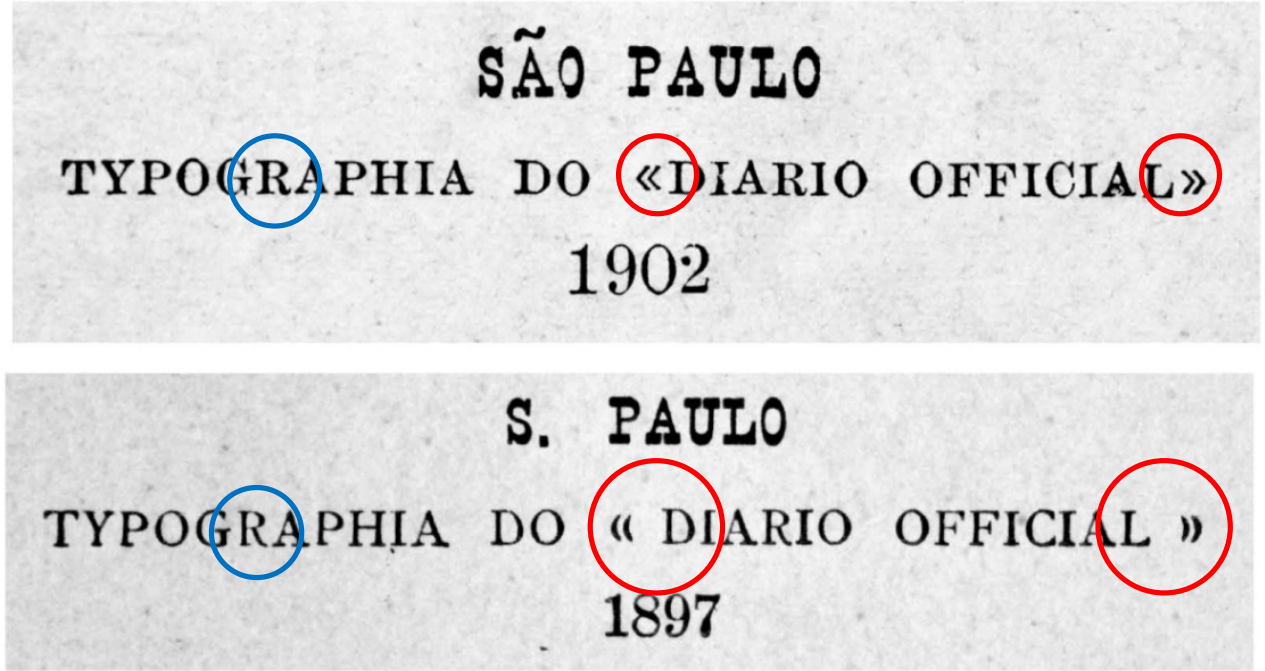

O uso de versaletes é outra característica notável. Imprentas também são entendidas como colofão e, segundo Arezio (1936), colofão corresponde ao:

Dístico final que aparecia nos manuscritos medievais, relativo ao autor ou escriba, ao lugar onde se escreveu a obra e à data. Assinatura do impressor, com a data em que foi concluída a impressão e o local da tipografia que imprimiu o trabalho, como faziam os antigos copistas. $O$ colofão era composto em versalete, em medida mais estreita que a estabelecida [grifo dos autores] (Arezio 1936: 134)

É possível que a prática do período revele costumes antigos de composição tipográfica, motivo pelo qual os tipos em versalete do conjunto estudado ainda eram usados na maioria das imprentas.

A análise também revelou que a mesma fonte usada na imprenta era usada para compor linhas de menor importância no título, como preposições ou conjunções. Este dado indica que as imprentas eram composições, sobretudo, discretas, que se relacionavam com as informações consideradas menos importantes no layout enquanto enaltecia a diversidade tipográfica das informações consideradas mais importantes (figura 9). 
Figura 9: fontes presentes em informações menores do título eram também usadas na composição da imprenta.

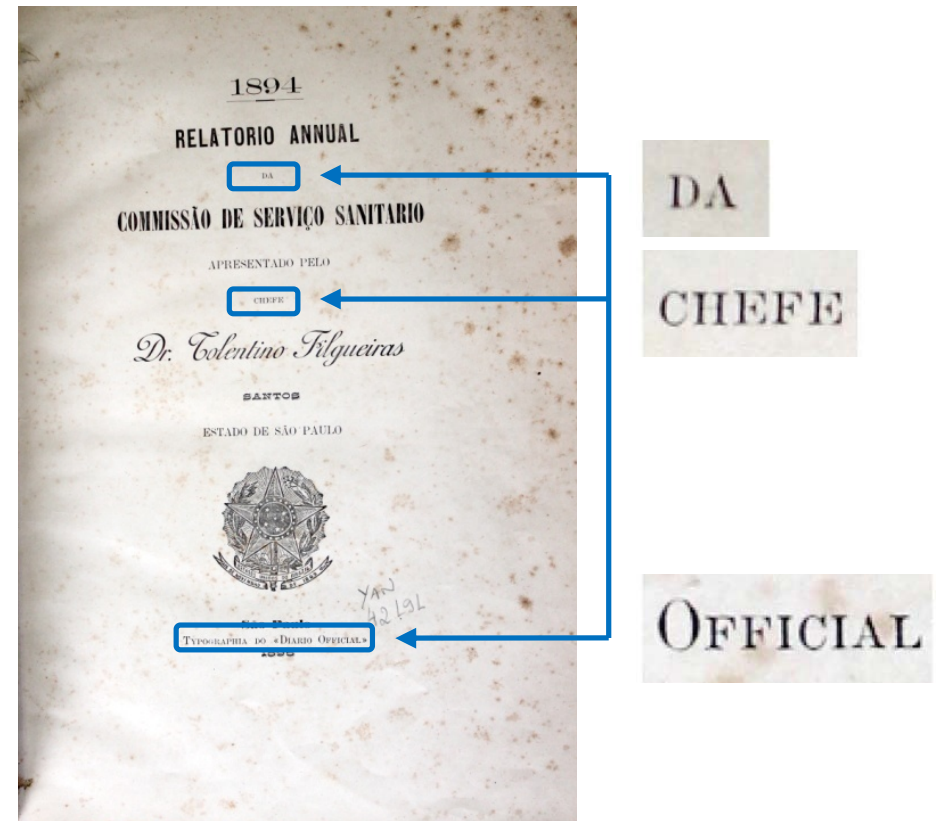

As principais características das assinaturas gráficas da Typographia do Diario Official observadas nas imprentas das folhas de rosto das publicações pesquisadas podem resumidas da seguinte forma:

- Não utilizam caracteres em caixa-baixa;

- Utilizam frequentemente versaletes;

- Utilizam frequentemente fontes classificadas como transicionais;

- Fontes usadas nas assinaturas também são usadas em elementos de menor importância presentes no título, como preposições, conjunções e artigos;

- As imprentas e as assinaturas gráficas nelas presentes são discretas. Os corpos pequenos que as compõem, bem como a localização na parte inferior da página, sugerem uma composição de presença sutil, com caráter essencialmente informativo.

\section{Considerações finais}

As assinaturas gráficas da Typographia do Diario Official, compostas em tipos pequenos e localizadas na região inferior das folhas de rosto, onde há menor destaque, revelam discrição em relação à comunicação institucional da oficina tipográfica, estando sua função mais ligada à informação que à associação de outros significados ao nome da empresa, qualidade comum em logotipos e marcas gráficas.

É importante reconhecer que o estudo se limitou a uma coleção advinda de acervos públicos estaduais e disponíveis para consulta presencial. Alguns volumes não foram encontrados fisicamente nos acervos e não puderam ser analisados. Também não se procurou esgotar as 
publicações dos primeiros vinte anos da Typographia do Diario Official. Uma catalogação exaustiva destas publicações foi realizada por Tálamo (1983), indicando diversas bibliotecas e acervos de obras raras em São Paulo e Rio de Janeiro. Entretanto, adotar tal catálogo, que reúne acervos geograficamente distantes, dificultaria sobremaneira a logística de visitas dentro do cronograma previsto para a realização deste trabalho. Um estudo mais amplo sobre as assinaturas gráficas da Typographia do Diario Official, contemplando acervo completo e recorte temporal mais extenso, pode fornecer novos dados sobre a comunicação institucional da oficina centenária, ou mesmo embasar novas perguntas sobre a história do design no Brasil.

A diversidade tipográfica encontrada nas folhas de rosto expõe parte dos tipos usados nas publicações oficiais do Estado de São Paulo no fim do século XIX e começo do XX. Um estudo sobre tal diversidade merece atenção por parte dos pesquisadores da história tipográfica brasileira.

\section{Agradecimentos}

Os autores agradecem o auxílio financeiro concedido pela Capes para realização desta pesquisa.

\section{Referências}

ARAGÃO, Isabella Ribeiro. 2016. Tipos móveis de metal da Funtimod: contribuições para a história tipográfica brasileira. Tese de doutorado. São Paulo: Faculdade de Arquitetura e Urbanismo da Universidade de São Paulo.

AREZIO, Arthur. 1936. Diccionario de termos graphicos. Salvador: Imprensa Official.

BARROS, José D'Assunção. jul/dez 2007. Sobre a feitura da micro-história. UFG: OPSIS. Vol. 7, n9.

BELLOTTO, Heloísa Liberalli. 2002. Como fazer análise diplomática e análise tipológica de documento de arquivo. São Paulo: Arquivo do Estado, Imprensa Oficial.

BRINGHURST, Robert. 2005. Elementos do estilo tipográfico. São Paulo: Cosac \& Naify.

DE VINNE, Theodore Low. 1904. Modern methods of book composition: a treatise on type-setting by hand by machine and on the proper arrangement and imposition of pages. New York: The Century Co.

DIARIO OFFICIAL. 27 set 1891. Regulamento interno para repartição do Diario Official e Typographia do Estado de S. Paulo. São Paulo, 1891. Disponível em: <www.imprensaoficial.com.br>. Acesso em: 20 nov 2017.

FRANÇA, Janaina de Avelar; SANT'ANNA, Hugo Cristo. 2006. Typographia Capitaniense: leis provinciais. 70 Congresso Brasileiro de Pesquisa e Desenvolvimento em Design. Curitiba. UTFPR, UFPR, UNICENP, UTP e PUC-PR.

GORDINHO, Margarida Cintra. 1991. Gráfica: arte e indústria no Brasil: 180 anos de história. São Paulo: Bandeirante.

IPANEMA, Cybelle de. 2008. A tipografia em São Paulo: contribuição à história de suas origens. São Paulo: Com-Arte. 
MARANHÃO, Ricardo (Coord.). 1994. Um retrato no jornal: a história de São Paulo na Imprensa Oficial (1891-1994). São Paulo: Imprensa Oficial do Estado.

MARTINS, Ana Luiza. 2008. Revistas em revista: imprensa e práticas culturais em tempos de República, São Paulo (1890-1922). São Paulo: Edusp.

NEWARK, Quentin. 2009. O que é design gráfico. Porto Alegre: Bookman.

O'GRADY, Jennifer Visocky; O'GRADY, Kenneth Visocky. 2008. The information design handbook. Crans-Près-Céligny: RotoVision.

PIAIA, Jade Samara. 2017. Memória gráfica em museus de arte: Pinacoteca do Estado de São Paulo. Tese de doutorado. Campinas: Unicamp.

ROSSI FILHO, Sérgio. 2001. GRAPHOS: glossário de termos técnicos em comunicação gráfica. São Paulo: Cone Sul.

SILVA, Fabio Luiz Carneiro Mourilhe; FARIAS, Priscila Lena. 2005. Um panorama das classificações tipográficas. Estudos em Design, v. 11, n. 2, p. 67-81.

STRUNCK, Gilberto L. T. L. 1989. Identidade visual: a direção do olhar. Rio de Janeiro: Europa.

TÁLAMO, Ivone (Coord.). 1983. Imprensa Oficial do Estado: 90 anos de produção gráfica, 18911981. São Paulo: Imprensa Oficial do Estado.

TRACY, Walter. 1971. Type design classification. Visible Language: the jounal for research on the visual media of language expression. Vol 5, n. 1, Cleveland: The Cleveland Museum of Art. (59-66).

TSCHICHOLD, Jan. 2007. A forma do livro: ensaios sobre tipografia e estética do livro. Cotia: Ateliê Editorial.

TWYMAN, M. 1979. A schema for the study of graphic language. In: KOLERS, P. A.; WROLSTAD, M. E. \& BOUMA, H. (Orgs.). Processing of Visible Language: 117-150. Nova lorque: Springer.

VILLAS-BOAS, André. Dez/2009. Sobre análise gráfica, ou Algumas estratégias didáticas para a difusão de um design crítico. Arcos Design: Rio de Janeiro, UERJ, ESDI, PPDESDI, n. 5.

VITORINO, Artur José Renda. 2000. Máquinas e operários: mudança técnica e sindicalismo gráfico (São Paulo e Rio de Janeiro, 1858-1912). São Paulo: Annablume. 